ORIGINAL ARTICLE

\title{
What is responsible for the carcinogenicity of $\mathrm{PM}_{2.5}$ ?
}

\author{
R M Harrison, D J T Smith, A J Kibble
}

Occup Environ Med 2004;61:799-805. doi: 10.1136/oem.2003.010504

\begin{abstract}
Aims: To test whether exposure to known chemical carcinogens in the atmosphere is capable of explaining the association between concentrations of $\mathrm{PM}_{2.5}$ and lung cancer mortality observed in the extended ACS Cohort Study. ${ }^{\text {' }}$

Methods: Taking account of possible cancer latency periods, lung cancer rates due to exposure to As, $\mathrm{Cr}(\mathrm{VI}), \mathrm{Ni}$, and polycyclic aromatic hydrocarbons (PAHs) were calculated based on a review of historic measurements from the United States and the use of unit risk factors. The predicted rates were compared with rates of cancer attributable to $\mathrm{PM}_{2.5}$ derived from data in the ACS study. ${ }^{1}$

Results: Despite many uncertainties, the lung cancer rates predicted due to exposure to US urban concentrations of the carcinogenic substances arsenic, nickel, chromium, and PAHs measured in 1960 and earlier (and hence allowing for a latency period) were within the range predicted on the basis of the ACS Cohort Study due to exposure of $\mathrm{PM}_{2.5}$. There are, however, many caveats, most particularly that for the chemical carcinogens to be responsible for the effects attributed to $\mathrm{PM}_{2.5}$ by Pope and colleagues, ${ }^{1}$ the concentrations of chemical carcinogens at the time of relevant exposures would need to be correlated with the concentrations of $\mathrm{PM}_{2.5}$ in US urban areas measured between 1979 and 2000 and used in the ACS study.

Conclusions: While many uncertainties remain, it appears plausible that known chemical carcinogens are responsible for the lung cancers attributed to $\mathrm{PM}_{2.5}$ exposure in the extended ACS Cohort Study. However, the possibility should not be ruled out that particulate matter is capable of causing lung cancer independent of the presence of known carcinogens.
\end{abstract}

See end of article for authors' affiliations

....................

Correspondence to: Professor R M Harrison, Division of Environmental Health \& Risk

Management, The University of Birmingham, Edgbaston, Birmingham B15 2TT, UK; r.m.harrison. ipe@bham.ac.uk

Accepted 24 March 2004
$\mathrm{T}$ here has long been evidence of higher lung cancer rates in urban than rural areas, especially among nonsmokers. For example, the Nashville Air Pollution Study $^{23}$ investigated the influence of social class and air pollution levels on the rates of various cancers, finding that of the four pollutants studied for their association with mortality from cancer (sulphur trioxide, soiling, dust fall, and sulphur dioxide), the most consistent pattern was for suspended particulate matter as measured by the soiling index. They noted that at that time no complete explanation was available for that observation. While the pollution monitoring methods were not specified in the published paper, soiling indices are generally determined from the blackness of filters used to collect airborne particulate matter ${ }^{4}$ and relate most typically to the airborne concentration of fine combustion particles, nowadays referred to as coefficient of haze or black smoke. ${ }^{5}$ In a study in the United Kingdom, Stocks and Campbell ${ }^{6}$ determined lung cancer death rates from mid-1952 to mid-1954 by age, smoking category, and population area divided according to rural, mixed, or urban character. A substantial increase in lung cancer rates was reported for urban areas, most pronounced among the nonsmokers. ${ }^{67}$ While such studies generally controlled for smoking prevalence, control for socioeconomic confounding and occupation related to place of residence was poor.

In the recently published extension to the American Cancer Society Study ${ }^{1}$ it was reported that fine particulate and sulphur oxide related pollution was associated with all cause lung cancer and cardiopulmonary mortality. Each $10 \mu \mathrm{g} \mathrm{m}^{-3}$ increase in fine particulate air pollution $\left(\mathrm{PM}_{2.5}\right)$ was associated with approximately a $4 \%, 6 \%$, and $8 \%$ increase in all cause, cardiopulmonary, and lung cancer mortality respectively. The study was a prospective study involving recruitment of approximately 1.2 million adult subjects commencing in 1982. Enrolment was restricted to persons aged 30 years or older who were assessed for individual risk and lifestyle factors including age, sex, weight, height, smoking history, alcohol use, occupational exposures, diet, education, marital status, and other characteristics. Vital status of study participants was ascertained at various points up to December 1998. Deaths were recorded according to cause of death. Each participant was assigned a metropolitan area of residence based on address at the time of enrolment, and death rates in the various metropolitan areas were analysed according to pollution indices including various measures of particulate matter $\left(\mathrm{PM}_{2.5}, \mathrm{PM}_{10}, \mathrm{PM}_{15}, \mathrm{PM}_{15-2.5}\right.$, TSP, and sulphate) and gases (sulphur dioxide, nitrogen dioxide, carbon monoxide, and ozone). Analysis of the results indicated a statistically significant association between the concentration of $\mathrm{PM}_{2.5}$ and all cause, cardiopulmonary, and lung cancer mortality. The relative risk of lung cancer mortality associated with a $10 \mu \mathrm{g} \mathrm{m}^{-3}$ change in $\mathrm{PM}_{2.5}$ was $8 \%$ using $\mathrm{PM}_{2.5}$ concentration data from 1979 to $1983,13 \%$ using $\mathrm{PM}_{2.5}$ data collected from 1999 to 2000, and 14\% when an average of the two sets of $\mathrm{PM}_{2.5}$ data was used. Unfortunately, $\mathrm{PM}_{2.5}$ data were not collected in the intervening period between 1983 and 1999, although a fairly consistent downward trend in $\mathrm{PM}_{2.5}$ concentrations was observed for the various metropolitan areas. The possibility that the results are explained by socioeconomic confounding is extremely low given the detailed individual level information included in the statistical analysis.

While the ACS study paper $^{1}$ provides a very detailed assessment of the risk factors for mortality in relation to pollutant exposure, it does not consider what causal agent is responsible for the association between mortality and $\mathrm{PM}_{2.5}$ exposure. In particular, the important question of whether the apparent carcinogenicity of $\mathrm{PM}_{2.5}$ is explicable in terms of its content of chemical carcinogens is not addressed, and it is questionable whether adequate data exist to make an assessment directly. If the concentrations of known chemical carcinogens were shown to be insufficient to account for the 


\section{Main messages}

- Allowing for a latency period of 20 years or more, concentrations of known chemical carcinogens in the atmosphere may be able to account for the carcinogenic effects of $\mathrm{PM}_{2.5}$ exposure as quantified in the American Cancer Society Study.

- If known chemical carcinogens (PAH, $\mathrm{Cr}, \mathrm{Ni}$, and $\mathrm{As}$ ) are responsible, their concentrations would need to have correlated with the $\mathrm{PM}_{2.5}$ concentrations of different cities. This has not been tested.

- It remains a possibility that $\mathrm{PM}_{2.5}$ may possess carcinogenic properties beyond those of the known chemical carcinogens which it contains.

demonstrated level of carcinogenicity of $\mathrm{PM}_{2.5}$, then it might have to be inferred that the particulate state of matter confers carcinogenicity on air pollutants irrespective of the presence of chemicals known to be capable of inducing lung cancer, or that other, hitherto unrecognised chemical carcinogens are present.

\section{METHODOLOGY AND RESULTS}

As noted above, the volunteers in the extended American Cancer Society Study were enrolled in 1982 and followed up until 1998. The data analysis ${ }^{1}$ uses air quality data for $\mathrm{PM}_{2.5}$ for periods between 1979 to 1983, and between 1999 to 2000 . It therefore analyses lung cancer rates in relation to contemporary concentrations of $\mathrm{PM}_{2.5}$ and other pollutants. Given that data from studies of cigarette smokers and lung cancer indicate a substantial latency period between commencement of exposure and expression of the cancer, it is reasonable to assume that this might apply also to air pollutant exposure and lung cancer, and if a 20 year latency period is assumed, relevant air pollutant exposures probably occurred between 1962 and 1978. We have therefore reviewed concentrations of known carcinogens in airborne particulate matter measured in US cities between the 1950s and 1990s. The data up to the late 1970s appear in fig 1 for concentrations of benzo(a)pyrene $(\mathrm{B}(\mathrm{a}) \mathrm{P})$, fig 2 for concentrations of arsenic, fig 3 for concentrations of chromium, and fig 4 for concentrations of airborne nickel. All graphs indicate that concentrations of these carcinogenic substances fell substantially between the early measurements in the 1950s and concentrations measured in the 1970s. Concentrations have fallen further in the intervening period, but not as steeply as during that period of substantial clean up. Typical concentrations from the review of published data for the years 1960, 1970, 1980, and 1990 appear in table 1.

In its Air Quality Guidelines for Europe, ${ }^{8}$ the World Health Organisation publishes unit risk factors for carcinogenic air pollutants. These factors are derived from occupational epidemiology assuming the absence of a threshold and a linear relation between attributable cancer incidence and the exposure to a chemical carcinogen. According to the World Health Organisation, ${ }^{8}$ the unit risk factors represent upper limit values for cancer risk. The WHO assessment indicates a lung cancer risk to be associated with the following substances: acrylonitrile, arsenic, chromium(VI), nickel compounds, polycyclic aromatic hydrocarbons (PAHs), refractory ceramic fibres, and trichloroethylene. Both acrylonitrile and trichloroethylene are industrial chemicals which have rather localised use and are not widespread urban pollutants. They are not monitored routinely in the outside atmosphere and any increases in atmospheric concentrations are likely to be

\section{Policy implications}

- In order to further reduce the carcinogenicity of ambient air revealed in the results of the American Cancer Society study, it may be necessary to abate airborne concentrations of $\mathrm{PM}_{2.5}$ as well as those of the chemical carcinogens which it contains.

relatively localised to the point of use. They have relatively low unit risks associated and have consequently been discounted as likely to be associated significantly with lung cancer in the general population. Similarly, refractory ceramic fibres are restricted primarily to the industrial environment and the risk to the general public is considered very low. Asbestos has been used far more widely, and at one time was used in brake pads. Measurements in the outdoor atmosphere are relatively few and tend to show very low concentrations. The lung cancer risk from environmental exposure to asbestos is considered to be very low. ${ }^{9}$ Having therefore excluded from consideration acrylonitrile, asbestos, refractory ceramic fibres, and trichloroethylene, the remaining lung carcinogens of potential importance are arsenic, chromium(VI), nickel compounds, and polycyclic aromatic hydrocarbons. It cannot be concluded with certainty that these are the only substances of significance, but they are the chemicals judged most likely to be responsible for lung cancer in the general population as a result of air pollution exposure. If chemical carcinogens present in the vapour phase were to correlate in concentration with airborne particles, they might explain an apparent carcinogenicity of $\mathrm{PM}_{2.5}$. However, the major non-particulate chemical carcinogens common in urban air-that is, benzene and 1,3-butadiene are associated primarily with leukaemia and are unlikely to be a significant cause of lung cancer. Polycyclic aromatic hydrocarbons are known to partition between the particulate and vapour phases, ${ }^{10}$ but the carcinogenic activity is known to lie almost wholly in the particle phase. The occupational cancer studies from which the unit risk factor for PAH has been derived are based on measurements of particulate benzo(a)pyrene as a marker for the mixture and implicitly allow for vapour phase PAH. While chromium and nickel both have compounds which can exist as vapours under atmospheric conditions (for example, nickel carbonyl), there is no evidence for their widespread presence in the atmosphere and the normal assumption is that both nickel and chromium in the atmosphere are present solely in a particle associated form.

The WHO unit risk factors have been combined with concentrations of airborne carcinogens typical of US cities in the various years examined to predict annual cancer rates. An example of the calculation appears in table 2. It should be noted that for chromium it is only the chromium(VI) form of the element which is carcinogenic, and in the absence of speciated data for chromium, it is assumed that all chromium measured in ambient air is in the carcinogenic $\mathrm{Cr}(\mathrm{VI})$ form, which will overestimate the cancer risk if less than $100 \%$ of $\mathrm{Cr}$ is in this form. If the carcinogenic effects are assumed additive and the results of these calculations are summed, the total lung cancer rate due to chemical carcinogens which appear in table 3 are estimated. These decrease very substantially between 1960 and 1990 .

Using lung cancer (ICD9 code 162) mortality rates as in Pope and colleagues ${ }^{1}$ for the United States derived from the Centres for Disease Control ${ }^{11}$ for 1980 and 1990 and the relative risks of lung cancer associated with $\mathrm{PM}_{2.5}$ exposure and average $\mathrm{PM}_{2.5}$ concentrations reported by Pope and 


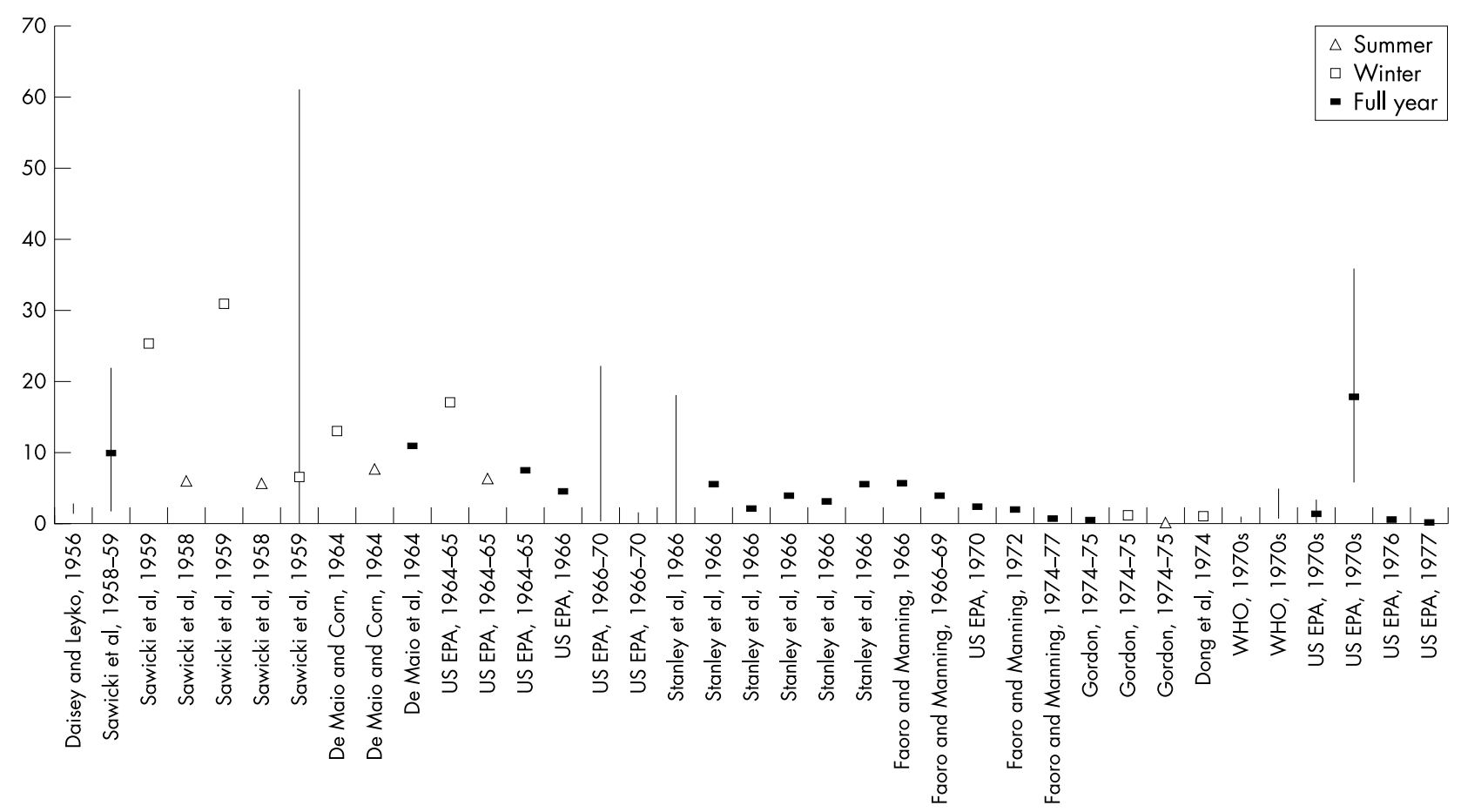

Figure 1 Range and mean benzo(a)pyrene concentrations $\left(\mathrm{ng} / \mathrm{m}^{3}\right.$ ) found in ambient air in cities in the USA during the 1950s to 1970s.

colleagues, ${ }^{1}$ the lung cancer mortality rate attributable to $\mathrm{PM}_{2.5}$ exposure in the United States has been calculated. In 1980 , based on the 1980 cancer mortality rate $\left(42.7\right.$ per $\left.10^{5}\right)$ and the 1979-83 data $\left(\mathrm{RR}=1.08\right.$ per $10 \mu \mathrm{g} \mathrm{m}^{-3} ; \mathrm{PM}_{2.5}=$ $21.1 \mathrm{\mu} \mathrm{m} \mathrm{m}^{-3}$ ) from Pope and colleagues, ${ }^{1}$ the lung cancer mortality attributable to $\mathrm{PM}_{2.5}$ was 7.2 (95\% CI 0.9 to 14.4 ) per $10^{5}$ population; using 1979-2000 average data from Pope and colleagues ${ }^{1}\left(\mathrm{RR}=1.13 ; \mathrm{PM}_{2.5}=14.0 \mu \mathrm{g} \mathrm{m}^{-3}\right)$ and the 1990 lung cancer mortality rate $\left(50.3\right.$ per $\left.10^{5}\right)$, it was 12.5 (95\% CI 3.6 to 20.5 ) per $10^{5}$ population. Since these mortality rates are derived from age standardised data they will underestimate rates in the ACS cohort who were enrolled only at age 30 and over. In the absence of knowledge of the age structure of the cohort, it is not possible to correct for this effect. Allowing for a latency period, these rates are tolerably close to the calculated rate for 1960 exposure to chemical carcinogens of 4.88 per $10^{5}$ population (table 3 ).

It should be recognised that the calculations based on unit risk factors are for rates of lung cancer, while the rates derived from the ACS study are for lung cancer mortality. However, since the five year survival from lung cancer in the United States over the period $1992-98$ was only $14.7 \%,{ }^{12}$ the

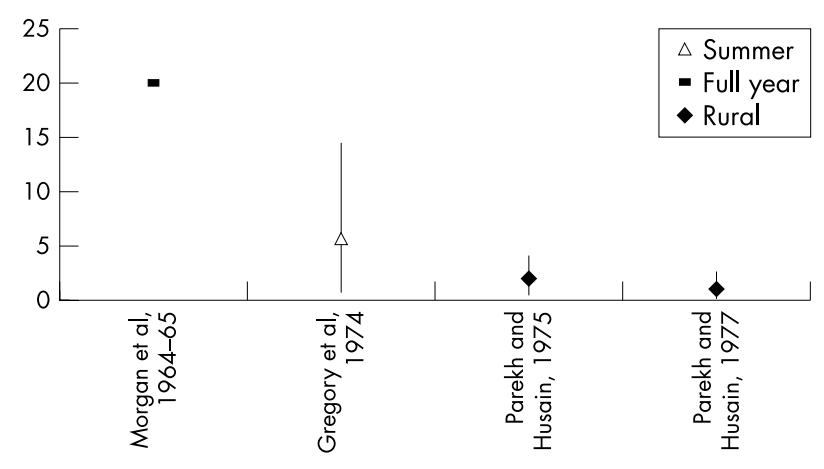

Figure 2 Range and mean arsenic concentrations $\left(\mathrm{ng} / \mathrm{m}^{3}\right)$ found in ambient air in cities in the USA during the 1950s to 1970s. difference is not large in the context of the uncertainty in these calculations.

\section{DISCUSSION}

The cancer rates above predicted on the basis of the ACS study ${ }^{1}$ relative risk and $\mathrm{PM}_{2.5}$ concentration data, and those from the chemical carcinogen concentrations allowing for a latency period and using WHO unit risk factors, are of a similar magnitude given the very substantial uncertainties surrounding this issue. These include the following:

- WHO unit risk factors are upper limit values, ${ }^{8}$ and therefore may overestimate lung cancer rates.

- It is unlikely that all airborne chromium is in the $\mathrm{Cr}(\mathrm{VI})$ oxidation state, and hence this assumption leads to an overestimation of the carcinogenic potential of the particulate matter. Recently reported measurements of the speciation of chromium in rainwater indicate roughly equal concentrations of dissolved $\mathrm{Cr}(\mathrm{VI})$ and $\mathrm{Cr}(\mathrm{III})$ with an undissolved chromium component (unlikely to be $\mathrm{Cr}(\mathrm{VI})$ ) of particles of almost equal concentration. ${ }^{13}$

- Lung cancer latency periods may be less than 20 years, in which case more recent exposures would appear unlikely to explain the extent of carcinogenicity. However, latency periods greater than 20 years would be more able to explain the observed carcinogenicity, as it is likely that pollutant concentrations were even higher in earlier years.

- The issue of biological latency for lung cancer is still the subject of much research. The literature most commonly cites an average latency period of at least 20 years (may be as high as 40-50 years) in people who smoke. Weiss suggests an approximate 30 year population latency period in both men and women smokers. ${ }^{14}$ Such latency periods are consistent with reported latencies for asbestos related lung cancer (25-35 years) and lung cancer risk associated with occupational exposure to carcinogens, for example, hexavalent chromium (20 years). ${ }^{15}$

- One of the problems in interpreting latency periods in smoking induced lung cancer is that there is considerable 


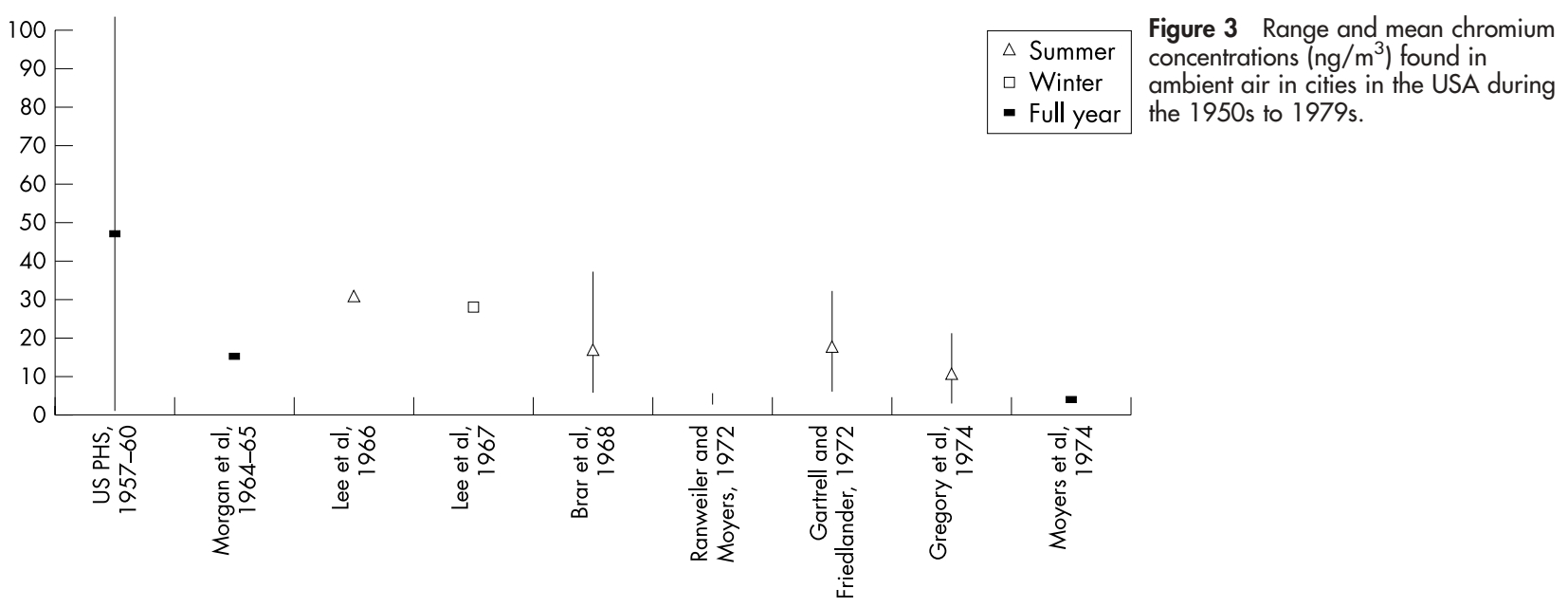

uncertainty surrounding whether a person's age at initiation of smoking is a risk factor for lung cancer independent of duration of smoking. At the moment, there is no consistent evidence that there is an association with age at smoking initiation and risk for lung cancer. ${ }^{16}$ Another factor which makes assessments of latency difficult is the possibility that the latency period will diminish as the dose is increased over time. It is likely that the latency period for lung cancer must be high. Most smokers begin at young ages, and since the age of diagnosis is rarely below 40 years and typically peaks around 65 years, ${ }^{16}$ the latency period must be over 20 years and probably in the range of 30-50 years. The striking time trends and sex differences seen in lung cancer mortality rates correlate with historical smoking patterns. ${ }^{14}$ The patterns in cigarette smoking between different birth cohorts have a strong but delayed effect on both incidence and death rates from cancer, leading to the progressive increase and later decrease in lung cancer incidence and mortality rates. ${ }^{17} 18$ Using time trends, it is clear that increases in lung cancer death rates parallel increases in cigarette consumption with a roughly 20-30 year lag time. ${ }^{14161920}$ It is also apparent that the uptake of regular cigarette smoking and reductions in smoking prevalence occurred earlier in men than in women in the United States. ${ }^{17} 19$ If $\mathrm{PM}_{2.5}$ exposure were to reduce the latency period in lung cancer, rather than act as an initiator, it would also serve to increase death rates.

- A major caveat of this approach is that if chemical carcinogens were responsible for the excess of lung cancer mortality associated with $\mathrm{PM}_{2.5}$ exposure as reported by Pope and colleagues, ${ }^{1}$ then airborne concentrations of the responsible chemical carcinogens would need to rank in the same way between metropolitan areas as the $\mathrm{PM}_{2.5}$ concentrations, unless the role of $\mathrm{PM}_{2.5}$ was to reduce the latency period rather than to induce the cancer. If the chemical carcinogen concentrations were uncorrelated with $\mathrm{PM}_{2.5}$ then they could not conceivably explain the findings of the study. Unfortunately, very few data are available from which to make any judgement as to whether such a correlation exists. However, published data $^{7}$ showed that within a single conurbation, Greater Birmingham, Alabama between 1964 and 1965, concentrations of total suspended particles were highly correlated with a range of individual particulate polycyclic aromatic hydrocarbons. This is not, however, the same as a correlation using data for a range of urban areas. However, when data from various cities measured by the US National Air Sampling Network in $1965^{21}$ are analysed, they show very modest correlations between total suspended particulate (TSP) concentration and chromium $\left(\mathrm{r}^{2}=0.214, \mathrm{n}=13\right)$, nickel $\left(\mathrm{r}^{2}=0.079, \mathrm{n}=17\right)$, and

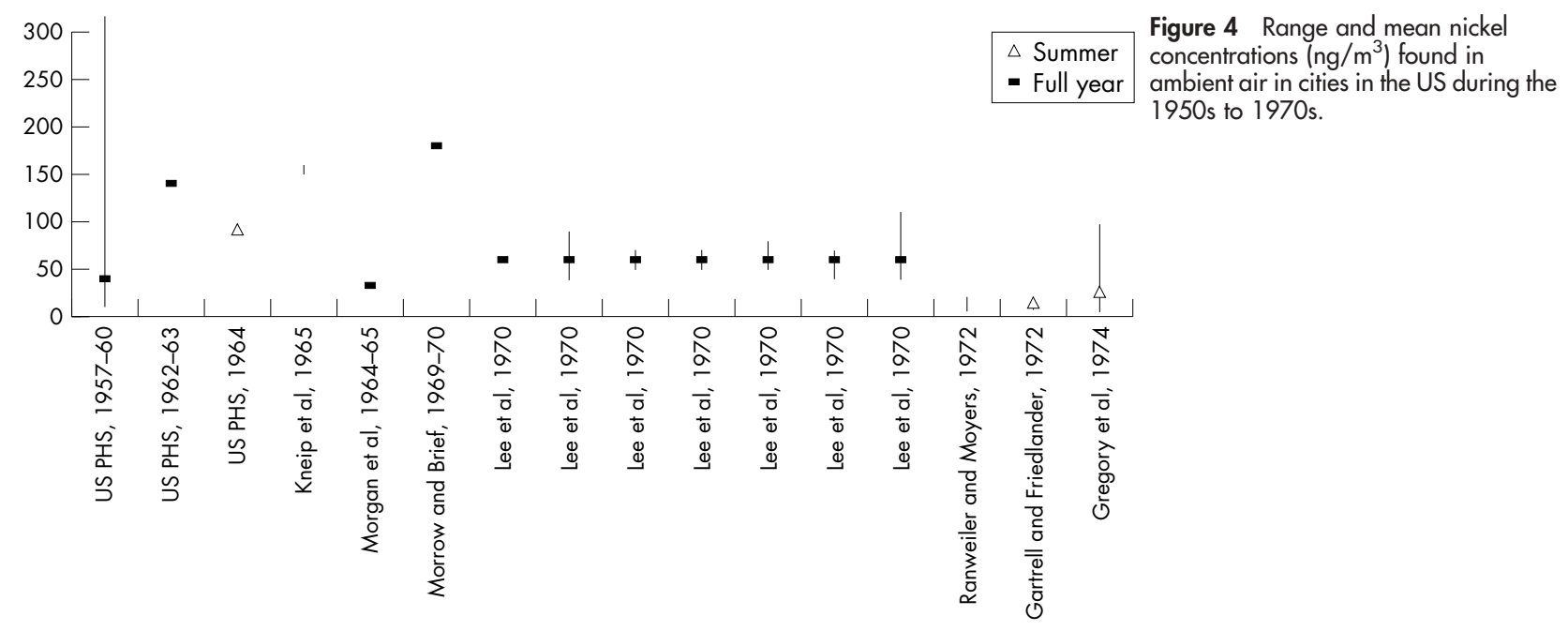




\begin{tabular}{|c|c|c|c|c|}
\hline \multirow[b]{2}{*}{ Pollutant } & \multicolumn{4}{|l|}{ Year } \\
\hline & 1960 & 1970 & 1980 & 1990 \\
\hline PAH (as B(a)P) & 20 & 4 & 1 & 0.5 \\
\hline $\mathrm{Cr}$ (all valence states) & 40 & 10 & 6 & 4 \\
\hline $\mathrm{Ni}$ & 100 & 60 & 20 & 10 \\
\hline As & 25 & 12 & 5 & 3 \\
\hline
\end{tabular}

benzo(a)pyrene $\left(\mathrm{r}^{2}=0.192, \mathrm{n}=99\right)$ concentrations. Unfortunately, measurements of $\mathrm{PM}_{2.5}$ were not made as part of that study. A study which examined relations between collocated annual $\mathrm{PM}_{10}$ and fine particle measurements ${ }^{22}$ showed highly variable ratios, and hence the two measurements are likely to be poorly correlated in a cross sectional sense. The results of the ACS Study ${ }^{1}$ show no significant effect of particle fractions (including $\mathrm{PM}_{10}$ and TSP) other than $\mathrm{PM}_{2.5}$ on lung cancer mortality. Given that the majority of the carcinogenic trace elements and polycyclic aromatic hydrocarbons would be concentrated in the finer particles (see below), it may well be that the correlation between these species and $\mathrm{PM}_{2.5}$ was much stronger than that with TSP, which can contain substantial coarser dust material also. Given the cancer latency period, it would be necessary for chemical carcinogen concentrations in 1960-80 to correlate with $\mathrm{PM}_{2.5}$ measured 20 years later cross sectionally across the cities. This is probably untestable due to a lack of adequate data.

For $\mathrm{PM}_{2.5}$ to be markedly carcinogenic relative to other fractions, it would be likely that the carcinogenic components would be focused in this size fraction. The evidence is that this is the case. With regards to PAHs in the UK, 95\% of particulate phase PAH sampled in London was found to be associated with aerosols less than $3.3 \mu \mathrm{m}$ in diameter, while during winter up to $82 \%$ was less than $1.1 \mu \mathrm{m} .{ }^{23}{ }^{24}$ In the USA, ${ }^{25}$ there are indications of the existence of a unimodal distribution for particulate phase PAHs, the peak being between 0.1 and $1 \mu \mathrm{m}$. The same study identified $75 \%$ of $\mathrm{B}(\mathrm{a}) \mathrm{P}$ to be associated with particles $<0.26 \mu \mathrm{m}$. Ambient air in Los Angeles has been found to have bimodal PAH distributions with peaks in the 0.05-0.12 and 0.5-1.0 $\mu \mathrm{m}$ size ranges. ${ }^{26}$

At an urban location in Birmingham (UK), Ni, Cr, and As were found to be present mostly in the fine fraction of particulate matter $(<2.1 \mu \mathrm{m}) .^{27}$ At a nearby $\operatorname{site}^{28}$ it was observed that the lower accumulation mode contained the largest mass concentration of Ni. Davison and colleagues ${ }^{29}$ reported that concentrations of toxic elements in fly ash from coal fired power stations increased markedly with decreasing particle size. With regard to the size distribution of metals components in US urban air, Lee and colleagues ${ }^{30}{ }^{31}$ found that the mass median diameter of $\mathrm{Cr}$ was between 1.5 and $1.9 \mu \mathrm{m}$ and that of Ni between 1.2 and $1.7 \mu \mathrm{m}$ in the urban air of Ohio. Source apportionment studies undertaken throughout cities in the USA, ${ }^{32}{ }^{33}$ have observed trace metals to be concentrated in the fine size fraction (fine fraction comprised $<2.5 \mu \mathrm{m}$ in the definitive "quail roost" source apportionment studies).

A point examined in detail by the Expert Panel on Air Quality Standards in the United Kingdom ${ }^{34}$ was whether benzo(a)pyrene represented a similar proportion of the carcinogenic potency of $\mathrm{PAH}$ in ambient air samples as in the epidemiological studies associating PAH exposure with lung cancer, which used benzo(a)pyrene as a marker of the
Table 2 Predicted cancer rates based on 1960 exposures to chemical carcinogens

\begin{tabular}{|c|c|c|c|}
\hline Pollutant & Conc. (ng m ${ }^{-3}$ ) & $\begin{array}{l}\text { Unit risk factor } \\
\left(\mathrm{ng} \mathrm{m}^{-3}\right)^{-1}\end{array}$ & $\begin{array}{l}\text { Annual cancer } \\
\text { rate (per } 10^{5} \\
\left.\text { pop }{ }^{n}\right)\end{array}$ \\
\hline PAH (as $B(a) P$ ) & 20 & $8.7 \times 10^{-5}$ & 2.49 \\
\hline $\mathrm{Cr}(\mathrm{VI})$ & $40^{*}$ & $4.0 \times 10^{-5}$ & 2.29 \\
\hline $\mathrm{Ni}$ & 100 & $3.8 \times 10^{-7}$ & 0.05 \\
\hline \multirow[t]{2}{*}{ As } & 25 & $1.5 \times 10^{-6}$ & 0.05 \\
\hline & & Total & 4.88 \\
\hline
\end{tabular}

whole PAH mixture. By recalculating the sum of the potential carcinogenic contributions (that is, product of concentration and relative potency $)^{34}$ of six individual PAHs measured in ambient air compared with that of $\mathrm{B}(\mathrm{a}) \mathrm{P}$ alone (which served as a reference compound), we found that benzo(a)pyrene represented $60-78 \%$ of the carcinogenic potency of the PAH mixture for US sites in the mid 1970s and early 1980s. This is broadly consistent with the relative contribution of $\mathrm{B}(\mathrm{a}) \mathrm{P}$ to the carcinogenicity of PAH in London, and in the atmosphere of an aluminium smelter from which occupational epidemiology data were used by the Expert Panel on Air Quality Standards to set an air quality standard. ${ }^{34}$ We therefore believe that changes in the composition of the mixture of PAH in ambient air are unlikely to have invalidated the use of benzo(a)pyrene as a marker and estimator of carcinogenicity.

The above analysis assumes that the various carcinogens act wholly independently of one another and do not depend on co-carcinogens whose concentrations may have also varied over the time period of study. This is probably a fair assumption for $\mathrm{PAH}$ and $\mathrm{Cr}(\mathrm{VI})$, which are generally believed to be primary (complete) genotoxic carcinogens, and represent the bulk of the carcinogenic activity in the airborne particles.

It seems likely, although very far from certain that the chemical carcinogen content of air in US cities in around 1960 would be sufficient to explain the increase in lung cancer mortality associated with $\mathrm{PM}_{2.5}$ concentrations some 20-40 years later. However, the question still arises as to whether particulate matter irrespective of its known chemical carcinogens may be responsible for causing lung cancer. Evidence from groups occupationally exposed to particulate matter indicates that a range of particulate material, including hardwood dust and welding fume, may cause nasal and lung cancer respectively. In the case of welding fume, known chemical carcinogens (for example, $\mathrm{Cr}$ ) may be present. Studies of workers exposed to diesel exhaust have revealed carcinogenicity, ${ }^{35}$ but the specific agents responsible have not been identified.

Studies on rats have repeatedly shown that chronic inhalation of high concentrations of particles, including particles of low toxicity, results in lung tumour formation. The likely mechanism behind such effects is that poorly soluble particles (PSP) overload the rat lung, which results in

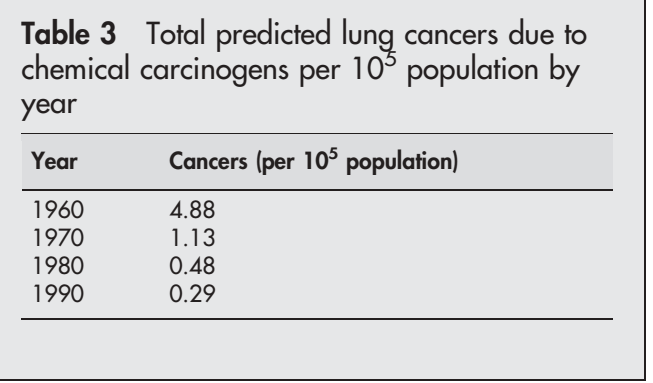


impaired alveolar clearance and subsequently chronic inflammation. ${ }^{36-38}$ It is the inflammatory response which is thought to play a key role in PSP induced lung tumours. Interestingly, while studies with rats show a statistically significant increase in the incidence of lung tumours under conditions of overload, similar results have not been seen in mice or hamsters. This inter-species difference between the rat and other rodent species implies that the possibility that humans will exhibit a different response to particle overload cannot be discounted. ${ }^{36}$

Particle overload has not been reported in human epidemiological studies, and human exposure to particles seldom results in overload. While occupational exposure to coal dust is clearly associated with increased risk of non-malignant effects in the lung, there is currently no convincing evidence of a statistically significant risk of lung cancer, ${ }^{36}$ although the particle size is relatively coarse and the surface area per unit mass consequently low. However, it is unlikely that coal dust exposure results in particle overload per se. The lack of any evidence of overload in humans suggests that any cancer effect associated with particles is very unlikely to be the result of a particle overload type mechanism. Current evidence suggests that at lower doses where overload and chronic inflammation does not occur, PSP exposures do not make a significant contribution to human lung cancer risk. ${ }^{36}{ }^{38}$ However, individuals with pre-existing diseases, such as those with chronic obstructive pulmonary disease or asthma, may already be exhibiting oxidative stress which may make them more susceptible to the effects of particle induced inflammation, ${ }^{37}$ perhaps at concentrations below overload levels.

Some particles may contain significant amounts of organic compounds or metals that could contribute to the overall carcinogenicity of the particle. Studies with rats on the overload effect show that tumours are initiated whether the particle is of low toxicity or contains carcinogens such as PAH. It has been suggested that the effect from these carcinogens is very low if not undetectable. ${ }^{38}$ At environmental concentrations (that is, below overload levels), it is likely that the composition of the particle plays a increasingly important role in possible particle induced cancers.

A number of recent papers have shown that particulate matter can induce oxidative DNA damage which is believed to be due to the generation of hydroxyl radicals by Fenton chemistry of trace metals contained with the particles. ${ }^{39}$ Recent work $^{40}$ has shown that in vitro particulate matter has the ability to cause specific DNA adducts that form through oxidative stress pathways. It is reported that the pathway from DNA adducts to accumulations of mutations culminating in transformation to a cancer cell is already well documented. ${ }^{41}$ There was no direct relation between the levels of single transition metals in the samples used in the above study ${ }^{40}$ and their ability to cause the DNA adducts, suggesting that factors other than metals might be involved in generating hydroxyl radical. ${ }^{41}$ The study did however show a greater effect overall with coarse fraction particles, although Donaldson comments that small particles aggregate and filter derived samples are not necessarily recovered in the same size fractions as they were present in the air. ${ }^{41}$ Clearly, there are substantial mechanistic uncertainties and the mechanisms by which the DNA adducts were formed are currently unclear. However, there may be mechanisms by which particles, irrespective of their content of known carcinogens are able to cause molecular changes leading to cancer.

Using a broadly similar approach to our own, Röösli and colleagues $^{42}$ have compared estimates of lung cancer risk derived from coefficients based on particulate matter mass concentration from the American cohort studies, including the ACS study, ${ }^{1}$ and the summed application of unit risk factors for a range of chemical carcinogens. The risk estimate derived from the former approach far exceeds that resulting from the application of unit risk factors. In both cases, however, contemporary air quality data were used, and no account was taken of cancer latency periods and changing levels of air pollution. ${ }^{42}$

\section{Conclusions}

The extended ACS cohort study ${ }^{1}$ gives an apparently unequivocal message that long term exposure to $\mathrm{PM}_{2.5}$ particulate matter leads to increased mortality due to lung cancer. Identifying the agent or agents responsible for carcinogenesis due to $\mathrm{PM}_{2.5}$ exposure has proved very difficult for a number of reasons, including the latency periods associated with lung cancer and hence the key period in relation to exposure to chemical carcinogens. If a latency period of at least 20 years is assumed, it is quite plausible that the known chemical carcinogens in urban air associated with particles may account for the observed carcinogenicity of $\mathrm{PM}_{2.5}$. However, the broad agreement between the cancer rates predicted from the unit risk factors and those observed in the ACS study in no way demonstrates causality. A key issue which is untestable in relation to the historic exposures is whether in a cross sectional analysis, airborne concentrations of chemical carcinogens in US cities at the key time for exposure correlated with the $\mathrm{PM}_{2.5}$ concentrations measured in the later years used to establish exposure-response relations in the ACS study. Evidence from occupational exposures to particulate matter and toxicological studies of the mechanisms of particle interactions with the lung suggest that there may be some plausibility in the concept of particulate matter irrespective of its content of chemical carcinogens being carcinogenic in its own right.

\section{Authors' affiliations}

R M Harrison, D J T Smith, A J Kibble, Division of Environmental Health \& Risk Management, The University of Birmingham, Edgbaston, Birmingham B15 2TT, UK

Dr Smith and Mr Kibble are now employed by the Health Protection Agency, Chemical Hazards and Poisons Division, Birmingham Centre.

\section{REFERENCES}

1 Pope III CA, Burnett RT, Thun MJ, et al. Lung cancer, cardiopulmonary mortality, and long-term exposure. JAMA 2002;287:1 132-41.

2 Hagstrom RM, Sprague HA, Tenn N, et al. The Nashville Air Pollution Study VII. Mortality from cancer in relation to air pollution. Arch Environ Health 1967; 15:237-46.

3 Zeidberg LD, Horton RJ, Landau E. The Nashville air pollution study: V. Mortality from diseases of the respiratory system in relation to air pollution. Arch Environ Health 1967;15:214-24.

4 APHA Inter-Society Committee. Methods of air sampling and analysis, 2nd edn., Methods 503. Washington, DC: American Public Health Association, 1977:588-91.

5 Edwards JD, Ogren JA, Weiss RE, et al. Particulate air pollutants: a comparison of British "smoke" with optical absorption and elemental carbon concentration. Atmos Environ 1983;17:2337-41.

6 Stocks $P$, Campbell JM. Lung cancer death rates amongst non-smokers and pipe and cigarette smokers. BMJ 1955;2:923-9.

7 US Environmental Protection Agency. Scientific and technical assessment report on particulate polycyclic organic matter(PPOM), EPA-600/6-75-001. 1975.

8 WHO. Air quality guidelines for Europe, 2nd edn. Copenhagen: World Health Organisation European Office, 2000.

9 Harrison PTC, Brown RC. Discussion and risk assessment of environmental exposure to fibrous materials. In: Fibrous materials in the environment. Leicester, UK: Institute for Environment and Health, 1997:95-106.

10 Smith DJT, Harrison RM. Polycyclic aromatic hydrocarbons in atmospheric particles. In: Harrison RM, van Grieken R, eds. Atmospheric particles John Wiley \& Sons, 1998.

11 Centers for Disease Control. Mortality trends for selected smoking-related cancers and breast cancers-United States, 1950-1990. MMWR 1993;42:645-9.

12 American Lung Association. Trends in lung cancer morbidity and mortality August 2002

13 Kieber RJ, Willey JD, Zvalaren SD. Chromium speciation in rainwater: temporal variability and atmospheric deposition. Environ Sci Technol 2002;36:5321-7. 
14 Weiss W. Cigarette smoking and lung cancer trends. A light at the end of the tunnel? Chest 1997;111:1414-16.

15 Hayes RB. Review of occupational epidemiology of chromium chemicals and respiratory cancer. Sci Total Environ 1988:71:331-9.

16 Bilello KS, Murin S, Mathay RA. Epidemiology, etiology and prevention of lung cancer. Clinics in Chest Medicine 2002;23:1-25.

17 Edwards BK, Howe HL, Ries LAG, et al. Annual report to the nation on the status of cancer, 1973-1999, featuring implications of age and aging on U.S. cancer burden. Cancer 2002;94:2766-92.

18 Mannino DM, Ford E, Giovino GA, et al. Lung cancer mortality rates in birth cohorts in the United States from 1960 to 1994. Lung Cancer 2001;31:91-9.

19 USEPA. Respiratory health effects of passive smoking: lung cancer and other disorders. USEPA Report: EPA/600/6-90/00F, December 1992.

20 Beckett WS. Epidemiology and etiology of lung cancer. Clinics in Chest Medicine 1993;14:1-15.

21 US PHS. Air quality data from the national air sampling networks and contributing state and local networks. US Dept of Health, Education and Welfare, 1996.

22 USEPA. Estimating PM10 and FP background concentrations from TSP and other measurements. EPA-450/4-84-021. Research Triangle Park, NC, 1984.

23 Baek SO, Goldstone ME, Kirk PWW, et al. Methodological aspects of measuring polycyclic aromatic hydrocarbons in the urban atmosphere. Environ Technol 1991;12:107-29.

24 Baek SO, Goldstone ME, Kirk PWW, et al. Phase distribution and particle-size dependency of polycyclic aromatic hydrocarbons in the urban atmosphere. Chemosphere 1991;22:503-20.

25 Miguel AH, Friendlander SK. Distribution of benzo(a)pyrene and coronene with respect to particle size in Pasadena aerosols in the submicron range. Atmos Environ 1978;12:2407-13.

26 Venkataraman C, Friedlander SK. Size distributions of polycyclic aromatic hydrocarbons and elements: sampling, measurement methods, and source characterization. Environ Sci Technol 1994:28:555-72.

27 Harrison RM, Smith DJT, Luhana L. Source apportionment of atmospheric polycyclic aromatic hydrocarbons collected from an urban location in Birmingham, UK. Environ Sci Technol 1996;30:825-32.

28 Allen AG, Nemitz E, Shi JP, et al. Size distributions of trace metals in atmospheric aerosols in the United Kingdom. Atmos Environ 2001;35:4581-91.

29 Davison RL, Natusch DFS, Wallace JR. Trace metals in fly ash: dependence of concentrations on particle size. Environ Sci Technol 1974;8:1107-13.

30 Lee RE, Patterson RK, Wagman J. Particle size distribution of metal components in urban air. Environ Sci Technol 1968;2:288-90.

31 Lee RE, Goranson SS, Enrione RE, et al. National Air Surveillance Cascade Impactor Network II: size distribution measurements of trace metal components. Environ Sci Technol 1972;6:1025-30.

32 Glover DM, Hopke PK, Vermette SJ, et al. Source apportionment with site specific source profiles. J Air Waste Manage Assoc 1991;41:294-305.

33 Gordon GE, Pierson WR, Daisey JM, et al. Considerations for design of source apportionment studies. Atmos Environ 1984;18:1567-82.

34 EPAQS. Polycyclic aromatic hydrocarbons. London: Expert Panel on Air Quality Standards, Department of Environment, Transport and the Regions, 1999.

35 HEI, Diesel Epidemiology Expert Panel. Diesel emissions and lung cancer: epidemiology and quantitative risk assessment. Special Report. Cambridge, MA: Health Effects Institute, 1999

36 ILSI Risk Science Institute Workshop Participants. The relevance of the rat lung response to particle overload for human risk assessment: a workshop consensus report. Inhalation Toxicology 2000;12:1-17.

37 Dick CA, Brown DM, Donaldson K, et al. The role of free radicals in the toxic and inflammatory effects of four different ultrafine particle types. Inhalation Toxicology 2003;15:39-52.

38 Oberdörster $\mathbf{D}$. Toxicokinetics and effects of fibrous and nonfibrous particles. Inhalation Toxicology 2002;14:29-56

39 Donaldson K, Li XY, MacNee W. Ultrafine (nanometre) particle mediated lung injury. J Aerosol Sci 1998;29:553-60.

40 Shi T, Knaapen AM, Begerow J, et al. Temporal variation of hydroxyl radical generation and 8-hydroxy-2'-deoxyguanosine formation by coarse and fine particulate matter. Occup Environ Med 2003;60:315-21.

41 Donaldson K. The biological effects of coarse and fine particulate matter. Occup Environ Med 2003;60:313-14.

42 Röösli M, Künzli N, Schindler C, et al. Single pollutant versus surrogate measure approaches: do single pollutant risk assessments underestimate the impact of air pollution on lung cancer risk? J Occup Environ Med 2003;7:715-23.

\section{REFERENCES APPEARING IN THE FIGURES}

Daisey JM, Leyko MA. Thin layer gas chromatographic method for the determination of polycyclic aromatic and aliphatic hydrocarbons in airborne particle matter. Anal Chem 1979;51:24-6.

Sawicki E, Elbert W, Stanley TW, et al. The detection and determination of polynuclear hydrocarbons in urban airborne polynuclear hydrocarbons in urban airborne particulates (I). Int J Air Pollut 1960;2:273-82.

Sawicki E, Elbert WC, Hauser TR, et al. Benzo(a)pyrene content of the air of American communities. Industrial Hygiene Journal 1960:4:443-51.

Demaio L, Corn M. Polynuclear aromatic hydrocarbons associated with

particulates in Pittsburgh air. Journal of Air Pollution Control 1966;16:67-71.

USEPA. Scientific and technical assessment report on particulate polycyclic organic matter (PPOM). Report no. EPA-600/6-75-001. USEPA, 1975.

Stanley TW, Morgan MJ, Grisby EM. Application of a rapid thin layer chromatographic procedure to the determination of benzo(a)pyrene, benzo(c)acrides, and benzo(de)anthracen-7-one in airborne particulates from many American cities. Environ Sci Technol 1968;2:699-702.

Faoro RB, Manning JA. Trends in benzo(a)pyrene. Journal of the Air Control Association 1981;31:62-4.

Cordon RJ. Distribution of airborne polycyclic aromatic hydrocarbons throughout Los Angeles. Environ Sci Technol 1976;10:370-3.

Dong M, Locke DC, Ferrand E. High pressure liquid chromatographic method for routine analysis of major parent polycyclic aromatic hydrocarbons in suspended particulate matter. Anal Chem 1976;46:368-72.

World Health Organisation. Series no. 23. Polynuclear aromatic hydrocarbons. In Air quality guidelines for Europe. WHO, 1987.

USEPA. Report no. EPA-600/7-80-044. POM source and ambient concentration data: review and analysis. USEPA, 1980.

Morgan GB, Ozolins G, Tabor EC. Air pollution surveillance systems. Science 1970;170:289-96.

Gregory K, Choquette CE, Gordon GE. Chemical element balances and identification of air pollution sources in Washington, D.C. Atmos Environ 1978:12:1143-53.

Parekh PP, Husain L. Trace element concentrations in summer aerosols at rural sites in New York and their possible sources. Atmos Environ 1981;15:1717-25. US Public Health Service (US PHS). Air Sampling Network, Publication no. 978. Air pollution measurements of the national air sampling network analysis of suspended particulates, 1957-61. 1962.

Morgan GB, Ozolins G, Tabor EC. Air pollution surveillance systems. Science 1970:170:289-96.

Lee RE, Patterson RK, Wagman J. Particle size distribution of metal components in urban air. Environ Sci Technol 1968;2:288-90.

Brar SS, Nelson DM, Kline JR, et al. Instrumental analysis for trace elements present in Chicago area surface air. J Geophys Res 1970;75:2929-45.

Ranweiler LE, Moyers JL. Atmospheric absorption procedures for analysis of metals in atmospheric particulate matter. Environ Sci Technol 1974;8:152-6. Cantrell G, Friedlander SK. Relating particulate pollution to sources: the 1972 California aerosol characterization study. Atmos Environ 1975:9:279-99.

Gregory K, Choquette CE, Cordon GE. Chemical element balances and identification of air pollution sources in Washington, D.C. Atmos Environ 1978;12:1143-53.

Moyers JL, Ranweiler LE, Hoff SB, et al. Evaluation of particulate trace species in southwest desert atmosphere. Environ Sci Technol 1977;11:789-95.

US Public Health Service (US PHS). Air Sampling Network, Publication no. 978 Air pollution measurements of the national air sampling network analysis of suspended particulates, 1957-61. 1962.

Kneip TJ, Klenman MT, Strehlow CD, Freidenthal PC. Trace metals in the atmosphere. Journal of the Air Control Association 1970;20:144-8. Morgan GB, Ozolins C, Tabor EC. Air pollution surveillance systems. Science 1970;170:289-96.

Morrow NL, Brief RJ. Elemental composition of suspended particulate matter in metropolitan New York. Environ Sci Technol 1971;5:786-9.

Lee RE, Goranson SS, Enrione RE, et al. National air surveillance cascade impactor network II. Size distribution measurements of trace metal components. Environ Sci Technol 1972;6:1025-30

Ranweiler LE, Moyers JL. Atomic absorption procedure for analysis of metals in atmospheric particulate matter. Environ Sci Technol 1974;8:152-6.

Cantrell G, Friedlander SK. Relating particulate pollution to sources: the 1977

California aerosol characterisation study. Atmos Environ 1975;9:279-99.

Gregory K, Croquette CC, Gordon GE. Chemical element balance and identification of air pollution sources in Washington, D.C. Atmos Environ 1978;12:1143-53. 